\title{
Impactos do cultivo por longo tempo de arroz inundado em Gleissolos
}

\author{
Gonçalves Jotamo Marrenjo(1), Eduane José de Pádua(2), Carlos Alberto Silva(2), \\ Plínio César Soares ${ }^{(3)}$ e Yuri Lopes Zinn ${ }^{(2)}$
}

\begin{abstract}
(1)Universidade Pedagógica, Delegação de Massinga, Caixa Postal 111, Maputo, Moçambique. E-mail: gjotamo@gmail.com (2)Universidade Federal de Lavras, Departamento deCiência doSolo, CaixaPostal3037,CEP37200-000Lavras, MG, Brasil.E-mail:eduanepadua@hotmail.com, csilva@dcs.ufla.br, ylzinn@dcs.ufla.br ${ }^{(3)}$ Empresa de Pesquisa Agropecuária de Minas Gerais Sudeste, Campus UFV, Caixa Postal 216, CEP 36571-000 Viçosa, MG, Brasil. E-mail: plinioc12@gmail.com
\end{abstract}

Resumo - O objetivo deste trabalho foi avaliar atributos do solo em resposta à diferentes usos da terra no Sul de Minas Gerais. Foram amostrados Gleissolos sob floresta nativa e cultivos de arroz (Oryza sativa) irrigado por inundação e de feijoeiro (Phaseolus vulgaris), bem como um Argissolo não inundável sob floresta nativa. O cultivo promoveu o aumento da densidade nos Gleissolos, até a profundidade de $0,4 \mathrm{~m}$, o que resultou em menores diâmetros médios geométrico e ponderado de agregados, especialmente para o arrozal sob inundação, cultivado anualmente com enxada rotativa. A análise micromorfológica do solo evidenciou que a compactação ocorreu em razão do menor espaço macroporoso entre agregados, bem como da menor porosidade derivada da atividade biológica. Os teores de $\mathrm{C}$ orgânico do solo (COS) e $\mathrm{N}$ total (N) nos Gleissolos cultivados foram cerca de 55 e 40\% menores do que no Gleissolo sob mata, em consequência da decomposição orgânica acelerada pelo cultivo. Contudo, o Gleissolo sob mata nativa apresentou teores e estoques de COS e N similares aos de um Argissolo sob mata, o que indica que o efeito da anaerobiose sobre a matéria orgânica do solo foi menor do que o esperado.

Termos para indexação: horizonte glei, matéria orgânica do solo, micromorfologia do solo, solos hidromórficos.

\section{Impacts of long-term cultivation of flooded rice in gley soils}

\begin{abstract}
The objective of this work was to evaluate soil attributes in response to different land use systems in the south of the state of Minas Gerais, Brazil. The soils sampled were gley soils under native forest, flooded rice (Oryza sativa) and common bean (Phaseolus vulgaris) croplands, as well as a dryland Ultisol under native forest. Cultivation increased bulk density in the gley soils, up to 0.4-m soil depth, which resulted in lower weighted mean diameter and lower geometric mean diameter of aggregates, especially for rice crops under flooding, annually tilled with rotary hoe. Micromorphological analyses of soil showed that soil compaction occurred due to the lower macroporosity among aggregates, as well as to the lower porosity derived from biological activity. Soil organic $\mathrm{C}$ (SOC) and total nitrogen $(\mathrm{N})$ in the cultivated gley soils were approximately 55 and $40 \%$ lower than in gley soil under native forest, as a consequence of accelerated organic decomposition caused by tillage. However, the gley soil under native forest showed contents and stocks of SOC and N similar to those of the Ultisol under forest, which suggests that the effect of anaerobiosis on soil organic matter was weaker than expected.
\end{abstract}

Index terms: gley horizon, soil organic matter, soil micromorphology, hydromorphic soils.

\section{Introdução}

Solos inundados são responsáveis por cerca de $80 \%$ da produção de arroz (Oryza sativa L.) no mundo e no Brasil (Sousa et al., 2009; Kögel-Knabner et al., 2010), o que é relevante, posto que o arroz é a principal fonte de carboidratos para metade da população humana (Kögel-Knabner et al., 2010). A inundação é uma das práticas agrícolas mais impactantes nos processos bioquímicos, que incluem: a menor eficiência da respiração heterotrófica (Abreu et al., 2007); a aceleração do intemperismo de minerais e lixiviação de íons; e a alteração das espécies mais comuns dos elementos de valência variável existentes no solo (Kögel-Knabner et al., 2010). O cultivo de arroz inundado se dá tipicamente em planícies de inundação fluvial e, portanto, em solos marcados pela anaerobiose, como os Gleissolos (Abreu et al., 2007; Mentges et al., 2013), mas também em Planossolos e Neossolos (Beutler et al., 2014). Como poucas culturas toleram 
essas condições, o cultivo anual do arroz é realizado de forma contínua numa mesma área, às vezes por séculos (Kögel-Knabner et al., 2010).

Embora a cultura do arroz inundado seja uma alternativa sustentável de uso de terras alagáveis, há também aspectos negativos no que se refere à qualidade do solo. A inundação periódica artificial ou natural afeta as propriedades físicas do solo, ao promover uma transição ainda pouco conhecida no padrão e estabilidade dos agregados, entre o período drenado e o inundado que, supostamente, seria pouco eficiente para a estabilização da matéria orgânica dentro de agregados (Rosa et al., 2011). Tal efeito desagregador é ainda maior, quando o solo é preparado com enxada rotativa após a inundação (puddling), antes da semeadura (Yan et al., 2013). Apesar de a decomposição de resíduos orgânicos em solos anaeróbicos ser mais lenta do que em aeróbicos (Abreu et al., 2007; Kögel-Knabner et al., 2010), tal desestruturação do solo pode acelerar perdas de $\mathrm{C}$ orgânico do solo (COS) e do $\mathrm{N}$ associado à matéria orgânica do solo. Contudo, em geral, as informações disponíveis sobre a dinâmica e as interrelações entre o COS, o $\mathrm{N}$ e a agregação, em cultivo de arroz inundado, são frequentemente contraditórias, pois, alguns trabalhos reportam degradação mútua desses indicadores, enquanto outros denotam o contrário (Lopes et al., 2006; Rosa et al., 2011). Tais contrastes são provavelmente decorrentes da complexidade das interações entre tipos de solo e manejos do arroz inundado, bem como de diferentes usos anteriores e tempo de uso. Como resultado, é difícil estabelecer um quadro geral de alterações esperadas nas diferentes propriedades de cada solo e, especialmente, sobre como os estoques de COS e $\mathrm{N}$ total seriam afetados. Tal carência de informação é crítica, em razão da importância do balanço de $\mathrm{C}$ nos diferentes usos da terra, dentre os quais se destaca o arroz inundado, plantado nos diferentes biomas no Brasil.

O objetivo deste trabalho foi avaliar atributos do solo em resposta à diferentes usos da terra no Sul de Minas Gerais.

\section{Material e Métodos}

As amostragens foram realizadas em Lambari, $\mathrm{MG}$, a $21^{\circ} 56^{\prime} 45^{\prime \prime} \mathrm{S}$ e $45^{\circ} 15^{\prime} 58^{\prime \prime} \mathrm{W}$, entre 870 e $880 \mathrm{~m}$ de altitude (Figura 1), área que compreende a planície de inundação do Córrego da Abadia e a Serra das Águas, onde predominam ortognaisses paleoproterozoicos e paragnaisses (Trow, 2008). A temperatura e precipitação médias anuais, em São Lourenço, cerca de $35 \mathrm{~km}$ a sudeste, são de $19,1^{\circ} \mathrm{C}$ e $1.569 \mathrm{~mm}$, respectivamente (Brasil, 1992). A planície de inundação, onde predomina o Gleissolo Háplico, é drenada artificialmente por canal aberto, que mantém o lençol freático à profundidade de pelo menos $0,6 \mathrm{~m}$. O solo predominante na Serra das Águas é um Argissolo bem drenado.

As hipóteses testadas foram as de que o cultivo de arroz inundado afeta consideravelmente a estrutura do solo, a retenção de COS e $\mathrm{N}$ total e as propriedades químicas, em relação à vegetação nativa. Assim, os tratamentos consistiram de: arroz inundado sobre Gleissolo; feijão de sequeiro sobre Gleissolo; mata nativa sobre Gleissolo; e mata nativa sobre Argissolo (Figura 1). A área de plantio de arroz, utilizada continuamente desde 1985, compreende experimentos de melhoramento genético, no Campo Experimental da Empresa de Pesquisa Agropecuária de Minas Gerais (Epamig). Os plantios são inundados artificialmente com lâmina d'água de $5-10 \mathrm{~cm}$, durante 4 a 5 meses por ano, entre outubro (plantio) e abril (colheita). A calagem é feita a cada 3-4 anos, conforme a necessidade, e a adubação é feita anualmente, com $500 \mathrm{~kg} \mathrm{ha}^{-1}$ de N- $\mathrm{P}_{2} \mathrm{O}_{5}-\mathrm{K}_{2} \mathrm{O}$ 8-28-16 aplicados ao sulco, e mais $200 \mathrm{~kg} \mathrm{ha}^{-1}$ de $\left(\mathrm{NH}_{4}\right)_{2} \mathrm{SO}_{4}$ aplicados à cobertura. A cada dois anos, são feitas aração e gradagem até $0,2 \mathrm{~m}$ de profundidade. Anualmente, após a inundação, usa-se a enxada rotativa (puddling) à profundidade de $0,2 \mathrm{~m}$, antes do plantio, que é feito em espaçamento de 0,2 a $0,3 \mathrm{~m}$ entre linhas e plantas, respectivamente. Após a drenagem e a colheita do arroz, a área é mantida sem cultivo, com crescimento espontâneo de ervas. A área de Gleissolo cultivada com feijoeiro (Phaseolus vulgaris L.), vizinha ao arrozal, e também pertencente à Epamig (Figura 1), é submetida a preparo do solo similar ao do arrozal, porém sem inundação anual e sem o uso da enxada rotativa. Como controle, amostrou-se um Gleissolo sob mata de galeria, sujeito à inundação periódica natural, ou seja, sem drenagem artificial, $3,6 \mathrm{~km}$ a jusante, às margens da rodovia BR-460 (Figura 1). Finalmente, como referência de um solo aeróbico, amostrou-se um Argissolo sob Floresta Estacional Semidecidual nativa, no Parque Estadual de Nova Baden, à altitude de $930 \mathrm{~m}$, aproximadamente $50 \mathrm{~m}$ acima da planície de inundação (Figura 1).

Em julho de 2014, o solo foi amostrado com três repetições, alocadas ao acaso em cada tratamento. Em cada repetição, abriu-se uma trincheira de $0,60 \mathrm{~m}$ de profundidade (Figura 2), para a descrição morfológica do 
perfil e a coleta de amostras às profundidades de $0-0,05$, 0,05-0,10, 0,10-0,20 e 0,20-0,40 m do solo. Amostras indeformadas, para a determinação da densidade do solo, foram coletadas com um anel de Kopecky, inserido verticalmente nas paredes da trincheira. Às mesmas profundidades, coletaram-se das paredes das trincheiras grandes torrões de solo, para fins de análise de estabilidade de agregados em água, granulometria,
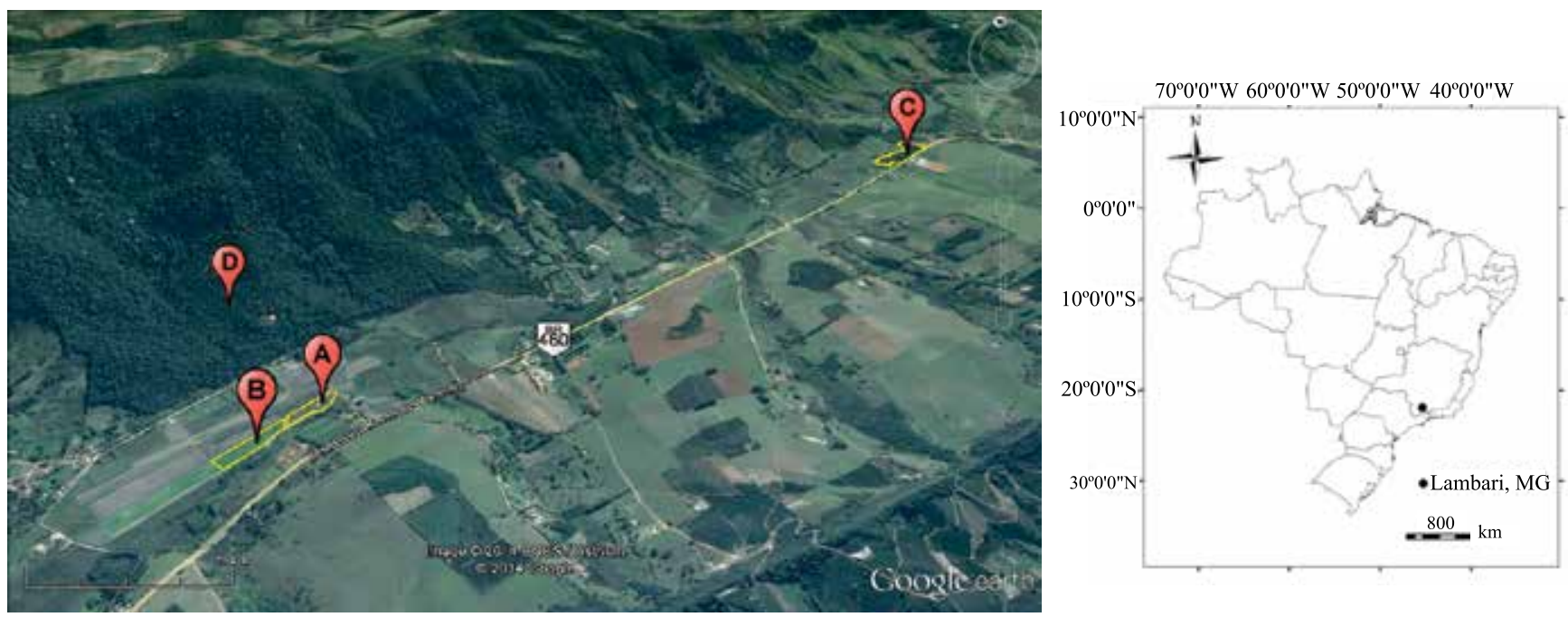

Figura 1. Área amostral em Lambari, MG. Os tratamentos ilustrados são: A, Gleissolo sob arroz inundado; B, Gleissolo sob cultivo de feijão; C, Gleissolo sob mata; e D, Argissolo sob mata. Fonte: Google Earth, acesso em 12/3/2015.
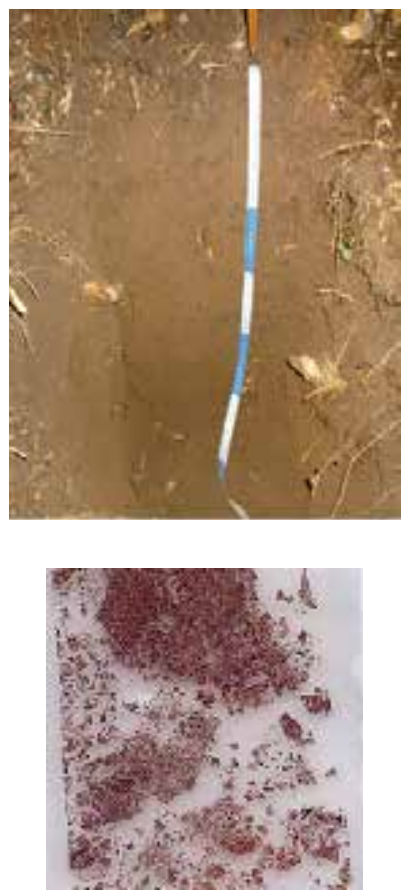

Argissolo sob mata
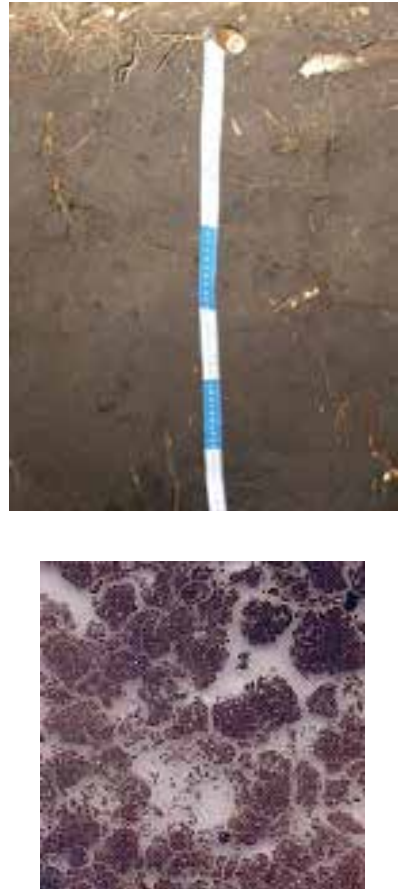

Gleissolo sob mata
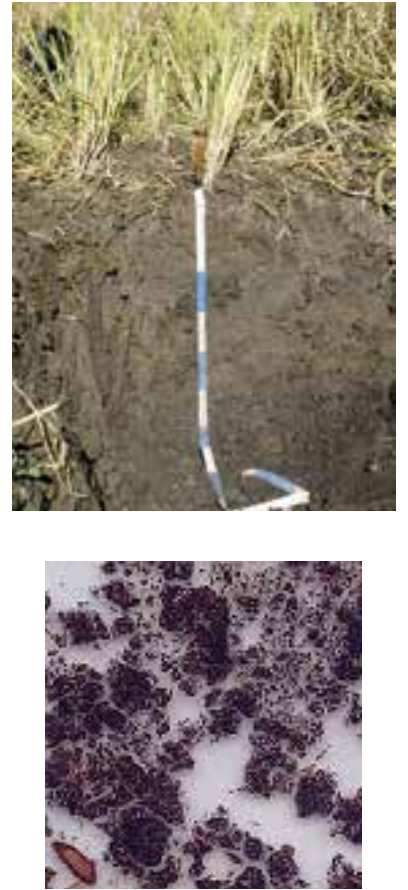

Gleissolo sob cultivo de arroz
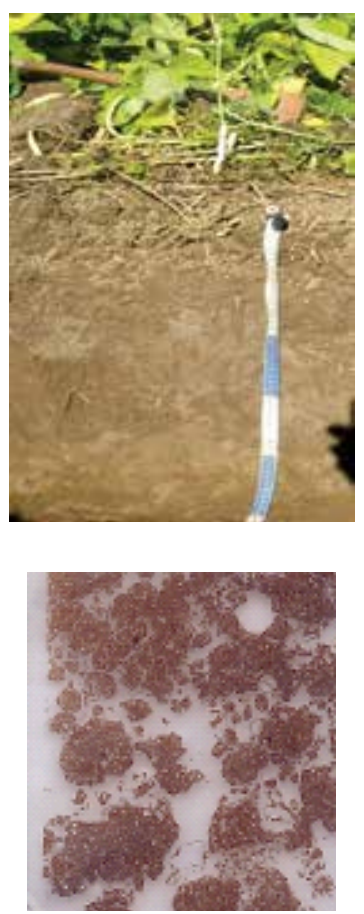

Gleissolo sob cultivo de feijão

Figura 2. Perfis dos solos amostrados e respectivas imagens digitalizadas das seções delgadas (imagens com $2,5 \mathrm{~cm}$ de largura), que mostram o padrão da estrutura. Note o grão de arroz em poro no Gleissolo sob arroz. 
caracterização química e teores de $\operatorname{COS}$ e $\mathrm{N}$ total. Amostras indeformadas de solo foram também coletadas para a descrição micromorfológica, em caixas de Kubiena de PVC, de uma camada superficial do solo com $7 \mathrm{~cm}$ de espessura, em apenas uma repetição por tratamento.

A densidade do solo (Ds) foi calculada, após secagem das amostras indeformadas de volume conhecido $\left(78,3 \mathrm{~cm}^{3}\right)$ em estufa a $105^{\circ} \mathrm{C}$, durante 24 horas. Torrões de solo foram secos ao ar, passados por malhas de 8 e $2 \mathrm{~mm}$, e o material maior do que $2 \mathrm{~mm}$ foi coletado para a análise de estabilidade de agregados em água. Pesaram-se $20 \mathrm{~g}$ de agregados de $8-2 \mathrm{~mm}$, que foram lentamente umedecidos com borrifador e colocados no topo, em conjunto de peneiras de malha 2, 1, 0,5, 0,25 e 0,105 mm, sujeitas a 25 oscilações verticais por minuto, durante $15 \mathrm{~min}$, em um reservatório de água. $\mathrm{O}$ material de amostras retidas em cada peneira foi seco a $105^{\circ} \mathrm{C}$, por 48 horas, e pesado para cálculo do diâmetro médio ponderado (DMP) e geométrico (DMG) dos agregados, segundo Nimmo \& Perkins (2002). A análise granulométrica foi realizada pelo método da pipeta, após dispersão em $\mathrm{NaOH}$ a $1 \mathrm{~mol} \mathrm{~L}^{-1}$ e agitação lenta por 16 horas, em amostras menores do que $2 \mathrm{~mm}$.

$\mathrm{O}$ pH do solo foi determinado em relação de 1:2,5

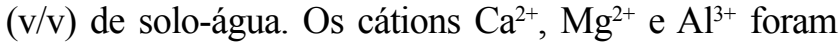
extraídos com $\mathrm{KCl}$ a $1 \mathrm{~mol} \mathrm{~L}^{-1}$, o $\mathrm{Ca}^{2+}$ e o $\mathrm{Mg}^{2+}$ foram determinados por absorção atômica, e $\mathrm{o} \mathrm{Al}^{3+}$ foi determinado por titulação com $\mathrm{NaOH}$ a $0,025 \mathrm{~mol} \mathrm{~L}^{-1}$. $\mathrm{O} \mathrm{K}^{+}$e o Pdisponíveis do solo foram extraídos por solução Mehlich-1 ( $\mathrm{HCl} \mathrm{0,05} \mathrm{mol} \mathrm{L-1}+\mathrm{H}_{2} \mathrm{SO}_{4}$ 0,025 mol L-1), o $\mathrm{K}^{+}$foi determinado por fotometria de chama, e o $\mathrm{P}$ por colorimetria com emprego do ácido ascórbico. A acidez potencial do solo foi determinada com acetato de cálcio a pH 7 e leitura potenciométrica, com base na solução SMP. O Fe e Mn disponíveis foram extraídos com solução Mehlich-1 e determinados por absorção atômica. $\mathrm{O}$ teor de COS foi determinado em amostras moídas em almofariz de ágata, por combustão a seco, em analisador Elementar, modelo Vario TOC Cube (Elementar, Hanau, Alemanha). O $\mathrm{N}$ total foi determinado pelo método de Kjeldahl, por destilação a vapor, conforme Claessen (1997), com uso da solução de $\mathrm{HCl} 0,07143 \mathrm{~mol} \mathrm{~L}^{-1}$ para a titulação. A partir dos teores de COS e $\mathrm{N}$ total, calculou-se a razão $\mathrm{C}: \mathrm{N}$. Os estoques de $\mathrm{COS}$ e $\mathrm{N}$ total foram calculados pelo método da massa equivalente, para compensar eventuais efeitos de compactação do solo.

As amostras indeformadas em caixas de Kubiena foram secas ao ar, por vários meses, depois em estufa a $60^{\circ} \mathrm{C}$, por três dias e, em seguida, a $100^{\circ} \mathrm{C}$ por 24 horas. Após esse processo de secagem, essas amostras foram impregnadas com resina epóxi, por três dias, a vácuo, para reduzir a formação de bolhas de ar. As amostras impregnadas foram endurecidas por 6 horas a $100^{\circ} \mathrm{C}$, curadas por 4 horas a $140^{\circ} \mathrm{C}$, e depois cortadas em serra diamantada, polidas e montadas em lâminas de vidro com resina epóxi. Seções delgadas foram desbastadas até a espessura de $30 \mu \mathrm{m}$ e descritas em microscópio petrográfico segundo critérios de Stoops (2003).

Utilizou-se o delineamento experimental inteiramente casualizado, com quatro tratamentos em quatro repetições, em quatro profundidades. Os dados obtidos foram submetidos à análise de variância e teste de Tukey, a 5\% de probabilidade, para comparação de médias, separadamente, para cada profundidade amostrada.

\section{Resultados e Discussão}

Os Gleissolos cultivados com arroz inundado e feijoeiro de sequeiro apresentaram composição granulométrica diferente daquela do controle (Tabela 1), com teores de argila menores do que no Gleissolo sob mata, para as mesmas profundidades. Os solos sob arroz

Tabela 1. Teores médios de areia e argila, densidade do solo (Ds), diâmetro médio geométrico (DMG) e ponderado (DMP) dos solos estudados ${ }^{(1)}$.

\begin{tabular}{|c|c|c|c|c|c|}
\hline Tratamento/Solo & $\begin{array}{c}\text { Areia } \\
\left(\mathrm{g} \mathrm{kg}^{-1}\right)\end{array}$ & $\begin{array}{l}\text { Argila } \\
\left(\mathrm{g} \mathrm{kg}^{-1}\right)\end{array}$ & $\begin{array}{c}\text { Ds } \\
\left(\mathrm{g} \mathrm{cm}^{-3}\right)\end{array}$ & $\begin{array}{l}\text { DMG } \\
(\mathrm{mm})\end{array}$ & $\begin{array}{l}\text { DMP } \\
(\mathrm{mm})\end{array}$ \\
\hline & \multicolumn{5}{|c|}{$0-0,05 \mathrm{~m}$} \\
\hline Mata/Argissolo & $390 \mathrm{a}$ & $476 \mathrm{ab}$ & $0,94 a b$ & $4,80 \mathrm{ab}$ & $4,92 \mathrm{ab}$ \\
\hline Mata/Gleissolo & $195 b$ & $574 a$ & $0,73 b$ & $4,92 \mathrm{a}$ & $4,97 \mathrm{a}$ \\
\hline Arroz/Gleissolo & $240 \mathrm{ab}$ & $381 b c$ & $1,07 \mathrm{a}$ & $3,79 \mathrm{c}$ & $4,48 \mathrm{c}$ \\
\hline \multirow[t]{2}{*}{ Feijão/Gleissolo } & $398 \mathrm{a}$ & $278 \mathrm{c}$ & $1,06 \mathrm{a}$ & $4,36 b$ & $4,72 \mathrm{bc}$ \\
\hline & \multicolumn{5}{|c|}{$0,05-0,10 \mathrm{~m}$} \\
\hline Mata/Argissolo & $400 \mathrm{a}$ & $469 \mathrm{ab}$ & $0,99 \mathrm{ab}$ & $4,73 \mathrm{ab}$ & $4,89 \mathrm{ab}$ \\
\hline Mata/Gleissolo & $216 \mathrm{c}$ & $569 a$ & $0,81 b$ & $4,88 \mathrm{a}$ & $4,96 a$ \\
\hline Arroz/Gleissolo & $239 \mathrm{ab}$ & $379 b c$ & $1,09 \mathrm{a}$ & $4,26 \mathrm{~b}$ & $4,67 b$ \\
\hline \multirow[t]{2}{*}{ Feijão/Gleissolo } & $390 \mathrm{ab}$ & $277 \mathrm{c}$ & $1,20 \mathrm{a}$ & $4,33 \mathrm{ab}$ & $4,70 \mathrm{~b}$ \\
\hline & \multicolumn{5}{|c|}{$0,10-0,20 \mathrm{~m}$} \\
\hline Mata/Argissolo & $382 \mathrm{a}$ & $492 \mathrm{ab}$ & $1,06 \mathrm{a}$ & $4,66 \mathrm{ab}$ & $4,85 \mathrm{ab}$ \\
\hline Mata/Gleissolo & $211 b$ & $575 a$ & $0,83 b$ & $4,90 \mathrm{a}$ & $4,97 \mathrm{a}$ \\
\hline Arroz/Gleissolo & $247 \mathrm{ab}$ & $377 \mathrm{bc}$ & $1,16 \mathrm{a}$ & $4,26 \mathrm{c}$ & $4,67 \mathrm{c}$ \\
\hline \multirow[t]{2}{*}{ Feijão/Gleissolo } & $393 a$ & $270 \mathrm{c}$ & $1,24 \mathrm{a}$ & $4,47 \mathrm{~b}$ & $4,77 \mathrm{ab}$ \\
\hline & \multicolumn{5}{|c|}{$0,20-0,40 \mathrm{~m}$} \\
\hline Mata/Argissolo & $350 \mathrm{a}$ & $533 a$ & $1,08 \mathrm{ab}$ & $4,56 \mathrm{ab}$ & $4,79 \mathrm{ab}$ \\
\hline Mata/Gleissolo & $324 a$ & $480 \mathrm{a}$ & $0,96 \mathrm{~b}$ & $4,79 \mathrm{a}$ & $4,93 \mathrm{a}$ \\
\hline Arroz/Gleissolo & $156 \mathrm{~b}$ & $438 \mathrm{a}$ & $1,04 \mathrm{ab}$ & $3,40 \mathrm{~b}$ & $4,18 b$ \\
\hline Feijão/Gleissolo & $411 \mathrm{a}$ & $272 b$ & $1,18 \mathrm{a}$ & $3,95 b$ & $4,54 \mathrm{ab}$ \\
\hline
\end{tabular}


e feijão apresentaram diferença de pelo menos $100 \mathrm{~g} \mathrm{~kg}^{-1}$ de teores de areia e argila para a mesma profundidade. Embora em solos sob inundação, cultivados com uso de enxada rotativa, possa ocorrer a perda de argila decorrente da dispersão das argilas (Kögel-Knabner et al., 2010), é mais provável que essas diferenças texturais ocorram em razão de processos deposicionais na planície de inundação (Thomas, 1994), especialmente mais próximo ao leito menor. $\mathrm{O}$ mesmo processo pode ter resultado nos maiores teores de argila do Gleissolo sob mata, 3,6 km a jusante. Porém, nos três Gleissolos amostrados, a textura é relativamente homogênea ao longo da profundidade amostrada, em especial nos solos cultivados, em consequência da mecanização. Em todos os solos, os grãos grosseiros de quartzo são de baixa esfericidade, angulares a subangulares, o que é consistente com a gênese a partir de rochas metamórficas e pouco transporte do material (Tabela 2). Os maiores teores de areia no Argissolo e Gleissolo sob feijão são visíveis ao microscópio petrográfico (Tabela 1), e as imagens mostram a maior quantidade de grãos brilhantes de quartzo e muscovita (grãos alongados e coloridos), inclusive como areia grossa $(>0,5 \mathrm{~mm}$ ) (Figuras $3 \mathrm{~A} \mathrm{e}$ $\mathrm{H})$.

O cultivo do arroz impactou negativamente a estrutura do solo, conforme denotado pelo decréscimo significativo no DMG e DMP, em todas as profundidades, em comparação ao Gleissolo sob mata (Tabela 1). Tal comportamento é habitualmente registrado em cultivos de arroz inundado, conforme verificado em Neossolo no Sul do Brasil (Beutler et al., 2014), em especial com o uso anual da enxada rotativa após a inundação (Yan et al., 2013). De fato, no presente trabalho, para o Gleissolo cultivado com feijão, em que a enxada rotativa não é utilizada, só houve redução significativa do DMP e DMG na camada superficial do solo (0-0,05 m), em comparação ao controle sob mata. Nota-se, ainda, que o DMP e DMG do Gleissolo sob mata não diferiram daquele do Argissolo, em acordo com a alta estabilidade de agregados dos solos tropicais sob vegetação nativa. A densidade dos dois solos sob mata aumentou com a profundidade (Tabela 1), conforme padrão modelado por Pádua et al. (2015) para esta região, mas a densidade não variou com a profundidade nos Gleissolos cultivados com arroz e feijoeiro. Observa-se, ainda, que o cultivo promoveu compactação significativa, sobretudo na camada superficial de $0,10-0,20 \mathrm{~m}$, em intensidade superior à registrada em um Gleissolo cultivado com arroz, por oito anos, no Rio Grande do Sul (Mentges et al., 2013). Assim, aceitou-se a hipótese de que o cultivo de arroz inundado e de feijoeiro afetam a estrutura do solo.

Uma análise visual da estrutura não perturbada dos solos amostrados (Figura 2) permitiu a interpretação qualitativa da desagregação e compactação, descritas pelos indicadores numéricos. O Argissolo sob

Tabela 2. Descrição morfológica e micromorfológica do horizonte subsuperficial dos solos e tratamentos amostrados.

\begin{tabular}{|c|c|c|}
\hline Tratamento/Solo & Descrição morfológica & Descrição micromorfológica \\
\hline Mata/Argissolo & $\begin{array}{l}\text { Estrutura - em blocos angulares a subangulares } \\
\text { - média e moderada; consistência dura, firme, } \\
\text { plástica; cerosidade comum e moderada; cor } \\
\text { úmida } 7,5 \text { YR } 4 / 3\end{array}$ & $\begin{array}{l}\text { Microestrutura em blocos subangulares; porosidade planar parcialmente } \\
\text { acomodada e cavitária; padrão de distribuição aleatório, limite g/f } 33 \mu \mathrm{m} \text { e } \\
\text { distribuição relativa porfírica fechada; material grosseiro - quartzo angular } \\
\text { dominante e mica; micromassa bruna - indiferenciada a cristalítica micácea; } \\
\text { pedofeições - excrementos em preenchimentos de canal. }\end{array}$ \\
\hline Mata/Gleissolo & $\begin{array}{l}\text { Estrutura em blocos subangulares a granular } \\
\text { média e moderada; consistência macia, friável, } \\
\text { muito plástica; cerosidade ausente; cor úmida } \\
2,5 Y 3 / 1\end{array}$ & $\begin{array}{l}\text { Microestrutura granular a grumosa; porosidade de empilhamento e planar } \\
\text { acomodada; padrão de distribuição aleatório, limite g/f } 33 \mu \mathrm{m} \text { e distribuição } \\
\text { relativa porfírica fechada; material grosseiro - quartzo subangular dominante } \\
\text { e mica; micromassa bruna indiferenciada a cristalítica micácea; pedofeições - } \\
\text { excrementos, esporos micorrízicos. }\end{array}$ \\
\hline Arroz/Gleissolo & $\begin{array}{l}\text { Estrutura maciça a granular média e moderada; } \\
\text { consistência macia, friável, muito plástica; } \\
\text { cerosidade ausente; cor úmida } 2,5 Y 3 / 1\end{array}$ & $\begin{array}{l}\text { Microestrutura em blocos subangulares; porosidade planar parcialmente } \\
\text { acomodada e cavitária; padrão de distribuição aleatório, limite g/f } 33 \mu \mathrm{m} \text { e } \\
\text { distribuição relativa porfírica fechada; material grosseiro - quartzo angular } \\
\text { dominante e mica; micromassa bruna indiferenciada a cristalítica micácea; } \\
\text { pedofeições - excrementos, algas diatomáceas }\end{array}$ \\
\hline Feijão/Gleissolo & $\begin{array}{l}\text { Estrutura em blocos subangulares a granular } \\
\text { média e moderada; consistência macia, friável, } \\
\text { muito plástica; cerosidade ausente; cor úmida } \\
10 \text { YR } 5 / 3\end{array}$ & $\begin{array}{l}\text { Microestrutura em blocos subangulares a grumosa; porosidade planar } \\
\text { parcialmente acomodada e cavitária; padrão de distribuição aleatório, limite } \\
\text { g/f } 33 \mu \mathrm{m} \text { e distribuição relativa porfírica fechada; material grosseiro - quartzo } \\
\text { angular dominante e mica; micromassa - bruna indiferenciada a cristalítica } \\
\text { micácea; pedofeições: nódulos de Fe e Mn, excrementos. }\end{array}$ \\
\hline
\end{tabular}



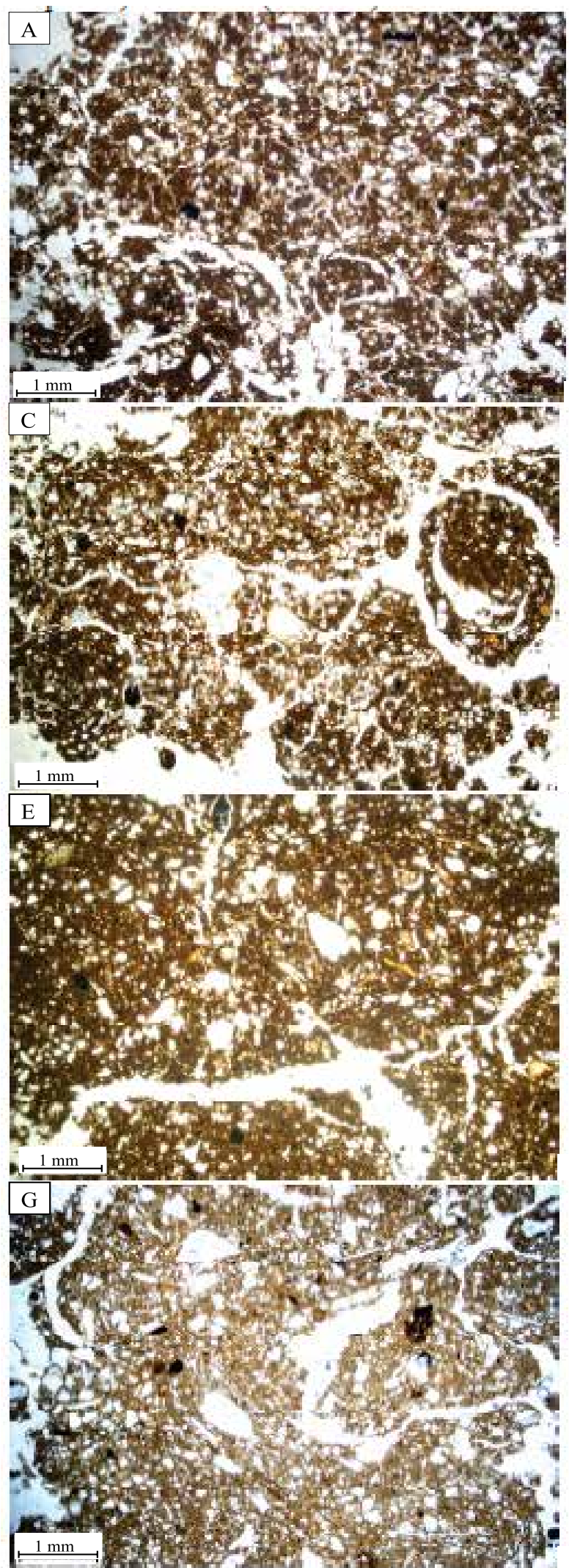
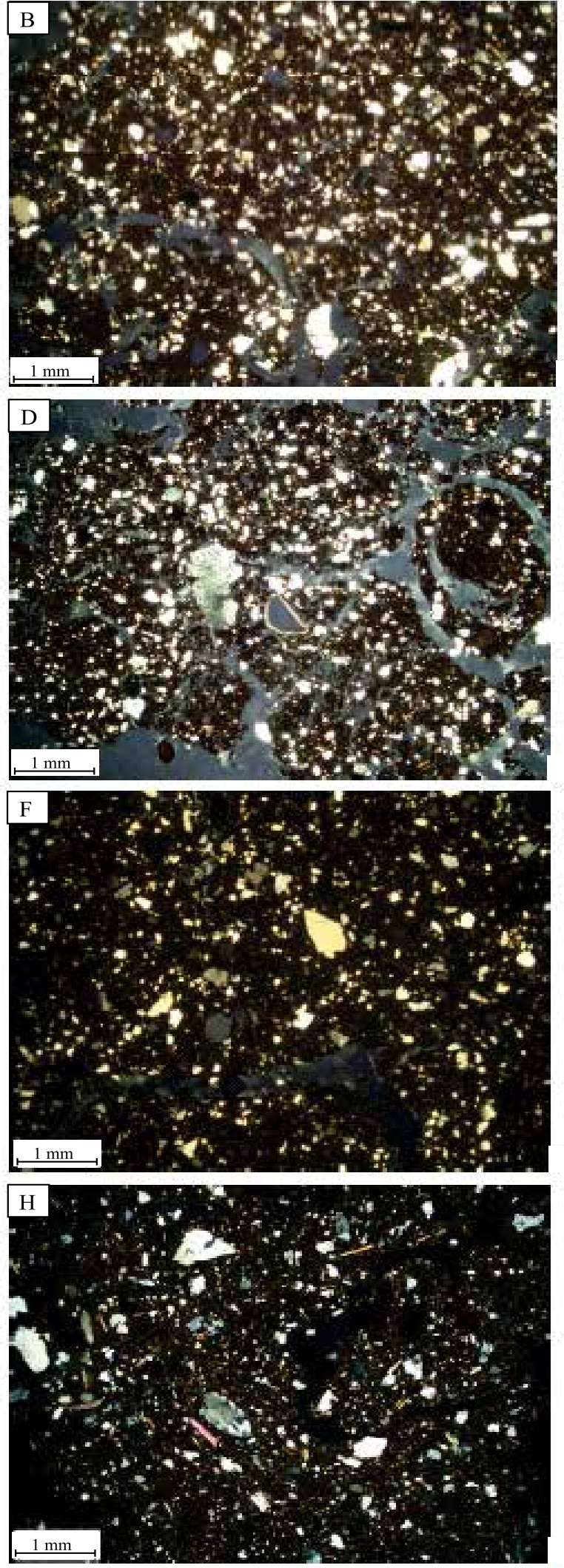

Figura 3. Microestrutura do solo superficial: A, B, mata sobre Argissolo; C, D, mata sob Gleissolo; E, F, arroz sob Gleissolo; G, H, feijão sob Gleissolo. Imagens obtidas sob luz polarizada planar (à esquerda) e cruzada (à direita). 
mata apresentou estrutura em blocos angulares e subangulares (Tabela 2) de diâmetro superior a $15 \mathrm{~mm}$, em contraste com o Gleissolo sob mata, que possui estrutura granular inferior a $10 \mathrm{~mm}$ e feições aparentes de contração esferoidal - entre e dentro dos peds (Figuras $3 \mathrm{C}$ e $3 \mathrm{D}$ ) - consistente com o alto teor de matéria orgânica (Tabela 3). Nos solos sob mata, verificou-se grande quantidade de microagregados granulares, em grandes poros de empacotamento (Figura 2), associado a uma atividade intensa de fauna escavadora do solo. Os esporos de fungos micorrízicos (Figuras $3 \mathrm{D}$ e $4 \mathrm{D}$ ) e os excrementos da fauna do solo foram mais comuns nos solos sob mata (Figura 4 B). Nos Gleissolos cultivados com arroz e feijão, o padrão de forma e tamanho dos macroagregados foi similar ao do Gleissolo sob mata, porém com menor importância dos microagregados coalescidos nos poros de empacotamento (Figura 2), o que indica menor atividade biológica em relação ao controle. Contudo, o cultivo dos Gleissolos com arroz inundado possibilitou atividade biológica diferenciada, conforme denotado pela ocorrência de algas diatomáceas (Figura $4 \mathrm{C}$ ), provavelmente da ordem Triceratiales, comuns em rios no Brasil (Burliga et al., 2005) e, portanto, na lâmina d'água do arrozal.

O aumento pronunciado da Ds nos solos cultivados refletiu não só a menor estabilidade de agregados

Tabela 3. Concentração média de $\mathrm{COS}, \mathrm{N}$ e razão C:N, para os diferentes usos do solo e profundidades ${ }^{(1)}$.

\begin{tabular}{lcccc}
\hline Tratamento/Solo & $0,0-0,05 \mathrm{~m}$ & $0,05-0,1 \mathrm{~m}$ & $0,1-0,2 \mathrm{~cm}$ & $0,2-0,4 \mathrm{~cm}$ \\
\hline & \multicolumn{4}{c}{$\mathrm{COS}\left(\mathrm{g} \mathrm{kg}^{-1}\right)$} \\
Mata/Argissolo & $49,4 \mathrm{AB}$ & $35,0 \mathrm{AB}$ & $29,9 \mathrm{AB}$ & $24,4 \mathrm{AB}$ \\
Mata/Gleissolo & $63,2 \mathrm{~A}$ & $56,3 \mathrm{~A}$ & $49,8 \mathrm{~A}$ & $41,3 \mathrm{~A}$ \\
Arroz/Gleissolo & $25,5 \mathrm{~B}$ & $25,0 \mathrm{~B}$ & $23,0 \mathrm{AB}$ & $18,3 \mathrm{~B}$ \\
Feijão/Gleissolo & $24,1 \mathrm{~B}$ & $21,8 \mathrm{~B}$ & $18,5 \mathrm{~B}$ & $15,1 \mathrm{~B}$ \\
\hline \multicolumn{5}{c}{$\mathrm{N}$ total $\left(\mathrm{g} \mathrm{kg}^{-1}\right)$} \\
Mata/Argissolo & $3,9 \mathrm{~A}$ & $3,7 \mathrm{~A}$ & $3,3 \mathrm{AB}$ & $2,2 \mathrm{~A}$ \\
Mata/Gleissolo & $4,9 \mathrm{~A}$ & $4,3 \mathrm{~A}$ & $3,9 \mathrm{~A}$ & $3,1 \mathrm{~A}$ \\
Arroz/Gleissolo & $3,1 \mathrm{~A}$ & $2,3 \mathrm{~B}$ & $2,2 \mathrm{~B}$ & $1,8 \mathrm{~A}$ \\
Feijão/Gleissolo & $3,1 \mathrm{~A}$ & $2,4 \mathrm{~B}$ & $2,3 \mathrm{AB}$ \\
\hline & \multicolumn{4}{c}{$1,9 \mathrm{~A}$} \\
Mata/Argissolo & $12,6 \mathrm{~A}$ & $9,46 \mathrm{~B}$ & $9,15 \mathrm{~B}$ & $11,2 \mathrm{AB}$ \\
Mata/Gleissolo & $12,8 \mathrm{~A}$ & $13,0 \mathrm{~A}$ & $12,6 \mathrm{~A}$ & $13,3 \mathrm{~A}$ \\
Arroz/Gleissolo & $9,16 \mathrm{~A}$ & $10,8 \mathrm{AB}$ & $10,6 \mathrm{AB}$ & $10,4 \mathrm{BC}$ \\
Feijão/Gleissolo & $8,25 \mathrm{~A}$ & $9,12 \mathrm{~B}$ & $8,26 \mathrm{~B}$ & $8,14 \mathrm{C}$ \\
\hline
\end{tabular}

${ }^{(1)}$ Médias seguidas de letras iguais, nas colunas, não diferem pelo teste de Tukey, a 5\% de probabilidade, para cada profundidade. em água, mas, em parte, também o forte decréscimo do teor de COS. O Gleissolo sob mata (Tabela 2) apresentou teores de $\operatorname{COS}$ muito maiores do que os Gleissolos cultivados (Tabela 3). Tal perda de COS, nos Gleissolos cultivados, decorre do uso intensivo de arados e grades que afetam a estrutura do solo, expõem o substrato orgânico à decomposição microbiana e aumentam a emissão de $\mathrm{CO}_{2}$ para a atmosfera (Yan et al., 2012; Zhang et al., 2014), além de proporcionar menor aporte de resíduos orgânicos em relação à mata. Contudo, apesar do uso da enxada rotativa no arrozal e seu efeito pulverizador no solo, não houve diferença significativa quanto aos teores de COS e $\mathrm{N}$ total entre os Gleissolos sob arroz e feijoeiro. É possível que o efeito prejudicial da enxada rotativa sobre o teor de COS, sob arrozal, tenha sido parcialmente compensado pela incorporação da palhada, durante o preparo do solo, e pela decomposição mais lenta durante a inundação (Abreu et al., 2007; Kögel-Knabner et al., 2010), de modo que não houve diferença em comparação ao Gleissolo sob feijão. Também não se observaram diferenças significativas quanto ao teor de $\mathrm{N}$ total, entre os dois Gleissolos cultivados (Tabela 3), apesar da fixação simbiótica de $\mathrm{N}$ atmosférico. Os maiores valores da razão $\mathrm{C}: \mathrm{N}$, observados no Gleissolo sob mata, se devem provavelmente ao maior aporte de $\mathrm{C}$ pela biomassa vegetal. Isto não se refletiu em C:N significativamente maior do que sob arroz, o que se explica pelas características da palhada do arroz. A razão $\mathrm{C}: \mathrm{N}$ do solo sob feijão foi sempre menor do que 10, o que é comum em solos sob leguminosas.

Em relação ao Gleissolo sob mata, o teor de COS decresceu 54 e $60 \%$, respectivamente, sob arroz inundado e feijão de sequeiro, em todas as profundidades (Tabela 3). Tais perdas foram muito superiores às reportadas por Lopes et al. (2006), de $16,7 \%$ sob cultivo do arroz (profundidade $0,0-0,10 \mathrm{~m}$ ) em um Gleissolo, em comparação à floresta nativa em Belém, PA. Essas perdas podem ser atribuídas aos altos teores de COS no Gleissolo sob mata, provavelmente derivados da temperatura média anual relativamente baixa, o que retarda sua decomposição. Em contraste, as perdas de $\mathrm{N}$ total foram bem menores - em média $40 \%$ nos Gleissolos sob arroz e feijão -, o que pode ser explicado pela imobilização imediata do $\mathrm{N}$ liberado durante a decomposição orgânica, enquanto o COS foi prontamente perdido como $\mathrm{CO}_{2}$ à atmosfera. Ainda, a mineralização do $\mathrm{N}$ é inibida em ambiente anaeróbico 
(Olk et al., 2007; Fageria et al.,2011) e, provavelmente, ocorre após o fim da inundação e colheita do arroz.

Os estoques de COS e $\mathrm{N}$ dos Gleissolos cultivados caíram mais de 50\%, em relação ao Gleissolo sob mata (Tabela 3, Figura 5), o que permitiu aceitar a hipótese de efeito significativo na retenção de COS e N. Tais perdas de COS são maiores do que o relatado quanto a um solo de várzea, cultivado por 21 anos com arroz, no Rio Grande de Sul (Rosa et al., 2011), com estoques $33,5 \%$ menores do que sob ecossistema natural a $20 \mathrm{~cm}$ de profundidade.
O Gleissolo sob mata não apresentou maiores estoques de COS e $\mathrm{N}$ do que o Argissolo sob mata, o que indica que o efeito da anaerobiose sobre a retenção de $\mathrm{C}$ não foi tão expressivo no ambiente estudado e reforça que os altos teores e estoques de COS sob mata decorrem da maior altitude local e consequente baixa temperatura média anual. Apesar desse potencial para grandes perdas de COS, com o cultivo de solos ricos em COS, o uso de sistemas de manejo conservacionista, como o plantio direto e o cultivo mínimo, pode diminuir a perda do COS
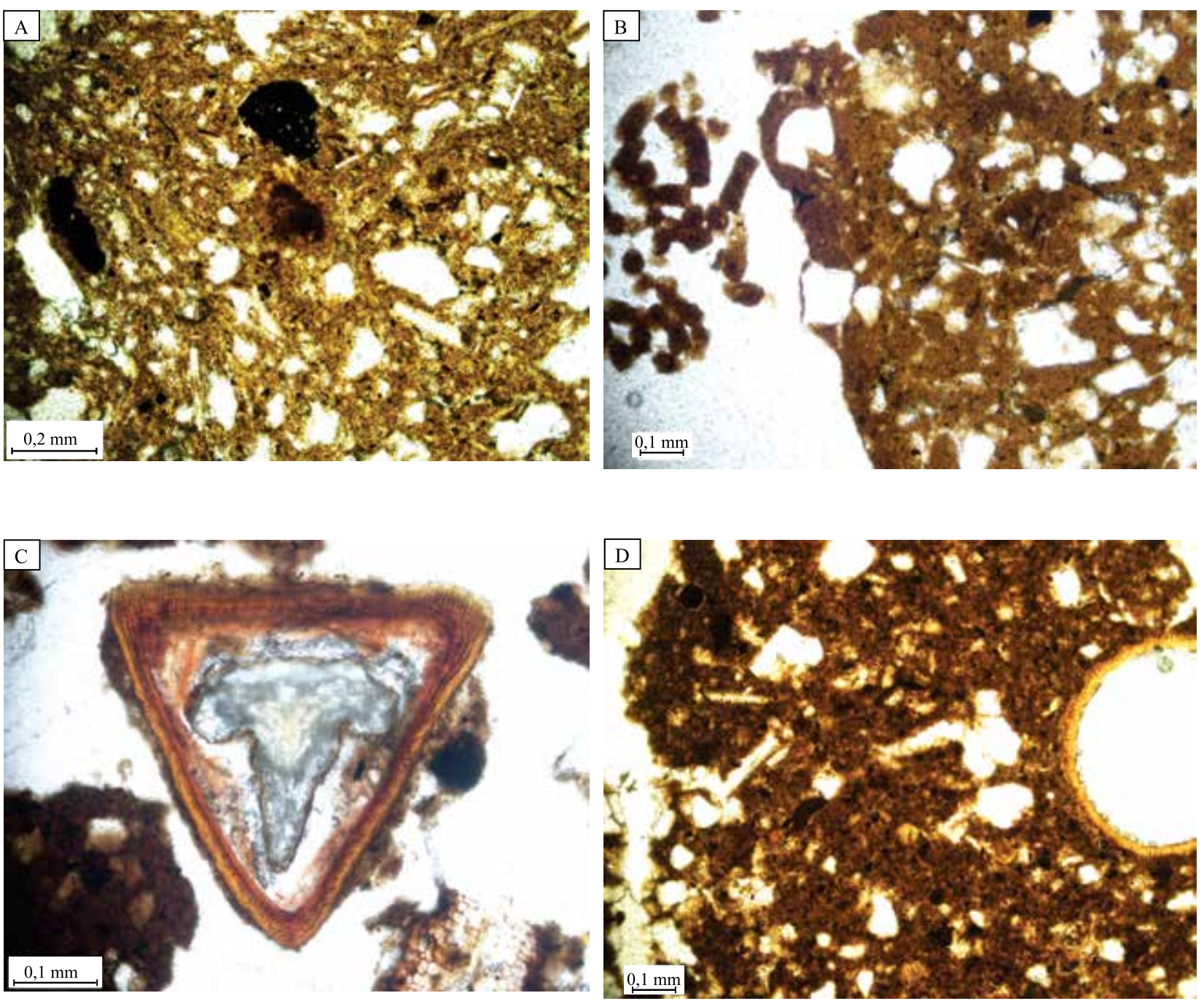

Figura 4. Feições pedológicas dos solos estudados: A, Gleissolo sob feijão, não mais sujeito à inundação sazonal, com nódulos de óxidos de Mn (pretos) e Fe (cor ferruginosa); B, excrementos, ricos em argila, no Argissolo sob mata; C, frústula (carapaça silicática) de alga diatomácea, no Gleissolo sob arroz inundado, com fragmento de tecido vegetal ao lado; e D, provável resto de esporo fúngico micorrízico, em Gleissolo sob mata. Imagens obtidas sob luz polarizada planar. 
(Rosa et al., 2011; Zhang et al., 2014). Nascimento et al. (2009) não reportaram diferenças dos estoques de COS em solos de várzea, com cultivo de arroz em plantio direto e vegetação nativa.

Os altos teores de COS nos solos sob mata explicam os maiores valores de acidez potencial $\left(\mathrm{H}^{+}+\mathrm{Al}^{3+}\right)$ das camadas intermediárias (Tabela 4), em razão da protonação de grupos carboxílicos presentes na matéria orgânica humificada. Em consequência disso, o pH do solo foi baixo - entre 4,53 e 5,50 (Tabela 4). Embora o $\mathrm{pH}$ tenha sido baixo em todos os tratamentos, os solos cultivados com arroz e feijão apresentaram valores próximos ao adequado para áreas agrícolas $(5,5-6,0)$, em consequência da calagem, que também tendeu a reduzir os teores de alumínio trocável. De fato, Fajardo et al. (2009) e Guimarães et al. (2013) mostraram que, acima de $\mathrm{pH} 5,5$, houve a quase anulação do $\mathrm{Al}^{3+}$ trocável em Gleissolos da Amazônia. A Tabela 4 apresenta a maior fertilidade para os Gleissolos cultivados sob mata, em razão da fertilização

Os teores de Fe e Mn em subsuperfície tenderam a ser maiores para o arroz inundado do que para os outros tratamentos, em consequência da maior solubilidade desses elementos na forma reduzida, em razão da inundação. $\mathrm{Na}$ área experimental amostrada, tais níveis de Fe são tóxicos para o arroz, de modo que somente variedades tolerantes são plantadas.

Finalmente, os padrões de mobilização e redeposição de $\mathrm{Fe}$ e $\mathrm{Mn}$, com a inundação periódica, se refletem na morfologia e micromorfologia dos solos (Tabela 2). Os Gleissolos sob mata ou arroz, quando amostrados úmidos, apresentaram cor cinzenta muito escura (2,5Y 3/1 de Munsell, Figura 2) que, após poucas horas de secagem, tornou-se muito mais clara (2,5Y 6/1), com poucos mosqueados milimétricos (5YR 4/2). Em contraste, observou-se cor seca brunada (7,5YR 4/3, Figura 2) no Argissolo e no Gleissolo sob feijão (10YR 5/3), porém, este apresentou nódulos órticos (gerados in situ e provavelmente recentes) de óxidos de $\mathrm{Mn}$ e Fe (Figuras $3 \mathrm{G}$ e $4 \mathrm{~A}$ ), o que é indicativo de sua estabilidade com a aerobiose permanente, proporcionada pela drenagem artificial do solo. Assim, nos Gleissolos sob mata e arroz, uma eventual formação sazonal de óxidos de $\mathrm{Fe}$ e $\mathrm{Mn}$, no período seco, seria provavelmente revertida no período alagado, o que resultaria nas cores gleizadas generalizadas e na ausência de mosqueados e nódulos estáveis. Assim, aceita-se, também, a hipótese de mudanças químicas nos solos cultivados, atribuídas à fertilização, inundação e drenagem artificiais.

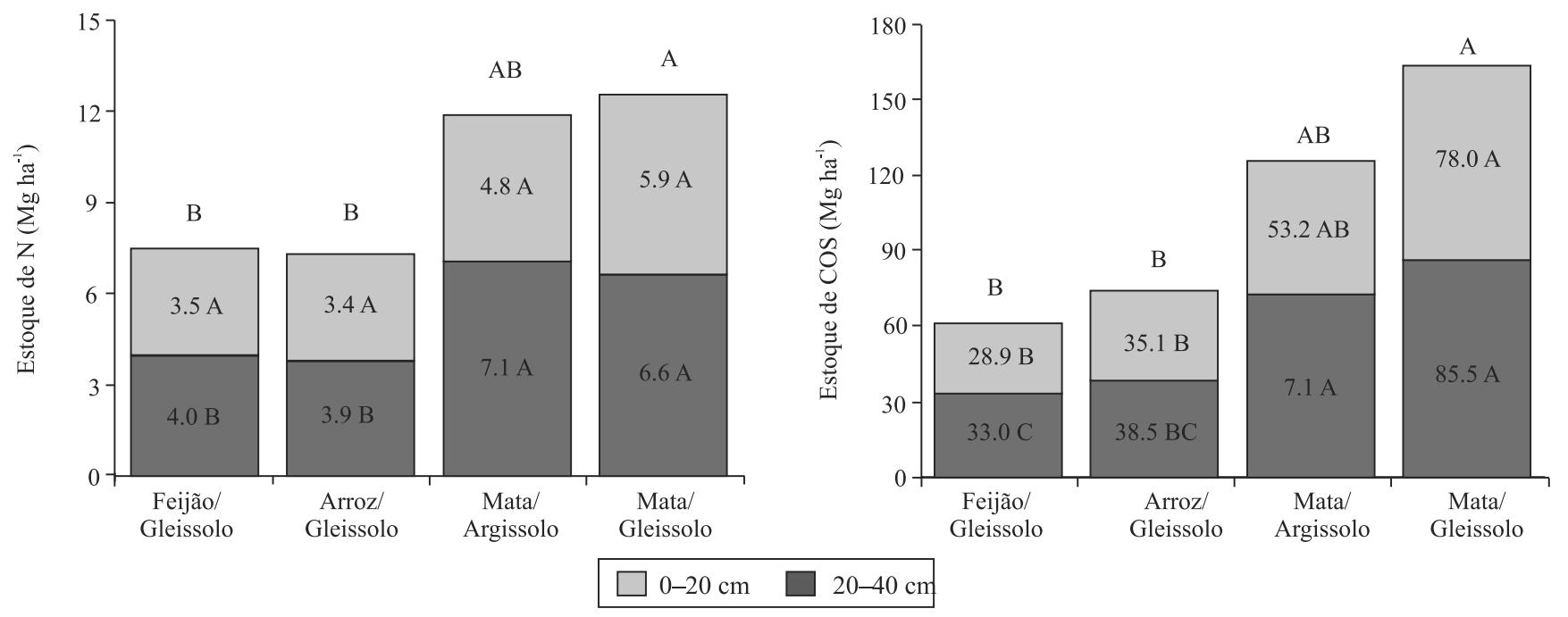

Figura 5. Estoques de COS e N, para duas profundidades, após correção para a compactação do solo. Colunas seguidas de letras iguais, por profundidade, não diferem pelo teste de Tukey, a 5\% de probabilidade. Letras no topo das colunas referem-se à camada de $0-40 \mathrm{~cm}$. 
Tabela 4. Atributos químicos do solo, para os diferentes usos do solo às profundidades $0-0,05,0,05-0,10,0,10-0,20 \mathrm{e}$ $0,20-0,40 \mathrm{~m}^{(1)}$.

\begin{tabular}{|c|c|c|c|c|c|c|c|}
\hline \multirow[t]{2}{*}{ Tratamento/Solo } & \multirow{2}{*}{$\begin{array}{c}\mathrm{pH} \\
\mathrm{H}_{2} \mathrm{O}\end{array}$} & $\mathrm{Al}^{3+}$ & $\mathrm{H}^{+}+\mathrm{Al}^{3+}$ & SB & \multirow[t]{2}{*}{$\mathrm{P}$} & $\mathrm{Fe}$ & \multirow{2}{*}{$\mathrm{Mn}$} \\
\hline & & -----------. & $\mathrm{cmol}_{\mathrm{c}} \mathrm{dm}^{-3}$ & ----_- & & $\left(\mathrm{mg} \mathrm{dm}^{-3}\right)$ & \\
\hline & \multicolumn{7}{|c|}{$0-0,05 \mathrm{~m}$} \\
\hline Mata/Argissolo & $5,07 \mathrm{~A}$ & $0,90 \mathrm{~A}$ & $9,83 \mathrm{~A}$ & $4,41 \mathrm{~A}$ & $3,11 \mathrm{~B}$ & $78,9 \mathrm{~B}$ & $57,7 \mathrm{~A}$ \\
\hline Mata/Gleissolo & $4,97 \mathrm{~A}$ & $1,90 \mathrm{~A}$ & $13,5 \mathrm{~A}$ & $2,14 \mathrm{~A}$ & $10,9 \mathrm{~B}$ & $172 \mathrm{AB}$ & $22,9 \mathrm{~A}$ \\
\hline Arroz/Gleissolo & $5,23 \mathrm{~A}$ & $0,77 \mathrm{~A}$ & $6,81 \mathrm{~A}$ & $3,02 \mathrm{~A}$ & $53,5 \mathrm{~A}$ & $317 \mathrm{~A}$ & $31,7 \mathrm{~A}$ \\
\hline \multirow[t]{2}{*}{ Feijão/Gleissolo } & $5,37 \mathrm{~A}$ & $0,43 \mathrm{~A}$ & $6,08 \mathrm{~A}$ & $3,90 \mathrm{~A}$ & $48,6 \mathrm{~A}$ & $184 \mathrm{AB}$ & $41,2 \mathrm{~A}$ \\
\hline & \multicolumn{7}{|c|}{$0,05-0,10 \mathrm{~m}$} \\
\hline Mata/Argissolo & $4,83 \mathrm{AB}$ & $1,33 \mathrm{AB}$ & $11,7 \mathrm{AB}$ & $1,75 \mathrm{~A}$ & $2,10 \mathrm{~B}$ & $69,5 \mathrm{C}$ & $33,5 \mathrm{~A}$ \\
\hline Mata/Gleissolo & $4,53 \mathrm{~B}$ & $1,93 \mathrm{~A}$ & $13,8 \mathrm{~A}$ & $1,11 \mathrm{~A}$ & $6,42 \mathrm{~B}$ & $103 \mathrm{C}$ & $7,40 \mathrm{~B}$ \\
\hline Arroz/Gleissolo & $5,33 \mathrm{~A}$ & $0,70 \mathrm{AB}$ & $6,55 \mathrm{C}$ & $3,31 \mathrm{~A}$ & $51,0 \mathrm{~A}$ & $336 \mathrm{~A}$ & $34,2 \mathrm{~A}$ \\
\hline \multirow[t]{2}{*}{ Feijão/Gleissolo } & $5,40 \mathrm{~A}$ & $0,63 \mathrm{~B}$ & $6,82 \mathrm{BC}$ & $3,46 \mathrm{~A}$ & $40,4 \mathrm{~A}$ & 197B & $35,6 \mathrm{~A}$ \\
\hline & \multicolumn{7}{|c|}{$0,10-0,20 \mathrm{~m}$} \\
\hline Mata/Argissolo & $4,70 \mathrm{~B}$ & $1,53 \mathrm{AB}$ & $12,1 \mathrm{~A}$ & $0,75 \mathrm{~B}$ & $1,90 \mathrm{C}$ & $69,0 \mathrm{C}$ & $22,4 \mathrm{~A}$ \\
\hline Mata/Gleissolo & $4,80 \mathrm{~B}$ & $1,77 \mathrm{~A}$ & $12,0 \mathrm{~A}$ & $0,37 \mathrm{~B}$ & $8,80 \mathrm{BC}$ & $41,6 \mathrm{C}$ & $0,57 \mathrm{~B}$ \\
\hline Arroz/Gleissolo & $5,40 \mathrm{~A}$ & $0,73 \mathrm{BC}$ & $6,79 \mathrm{~B}$ & $3,22 \mathrm{~A}$ & $48,7 \mathrm{~A}$ & $352 \mathrm{~A}$ & $36,1 \mathrm{~A}$ \\
\hline \multirow[t]{2}{*}{ Feijão/Gleissolo } & $5,50 \mathrm{~A}$ & $0,60 \mathrm{C}$ & $5,86 \mathrm{~B}$ & $3,03 \mathrm{~A}$ & $27,3 \mathrm{AB}$ & 189B & $26,6 \mathrm{~A}$ \\
\hline & \multicolumn{7}{|c|}{$0,20-0,40 \mathrm{~m}$} \\
\hline Mata/Argissolo & $4,90 \mathrm{AB}$ & $1,53 \mathrm{AB}$ & $12,3 \mathrm{~A}$ & $0,32 \mathrm{~B}$ & $1,03 \mathrm{~B}$ & $55,6 \mathrm{~B}$ & $11,9 \mathrm{BC}$ \\
\hline Mata/Gleissolo & $4,83 \mathrm{~B}$ & $1,60 \mathrm{AB}$ & $11,5 \mathrm{~A}$ & $0,64 \mathrm{~B}$ & $8,13 \mathrm{AB}$ & $41,5 \mathrm{~B}$ & $1,31 \mathrm{C}$ \\
\hline Arroz/Gleissolo & $5,17 \mathrm{AB}$ & $1,83 \mathrm{~A}$ & $10,3 \mathrm{~A}$ & $1,78 \mathrm{~A}$ & $13,1 \mathrm{~A}$ & $287 \mathrm{~A}$ & $38,1 \mathrm{~A}$ \\
\hline Feijão/Gleissolo & $5,43 \mathrm{~A}$ & $0,97 \mathrm{~B}$ & $6,79 \mathrm{~A}$ & $1,96 \mathrm{~A}$ & $7,77 \mathrm{AB}$ & $120 \mathrm{~B}$ & $20,9 \mathrm{~B}$ \\
\hline
\end{tabular}

${ }^{(1)}$ Médias seguidas de letras iguais, para cada profundidade nas colunas, não diferem pelo teste de Tukey, a $5 \%$ de probabilidade. SB, soma de bases trocáveis.

\section{Conclusões}

1. O cultivo de Gleissolos - drenados artificialmente - com o arroz inundado e com feijão em sequeiro provoca compactação até $40 \mathrm{~cm}$ de profundidade e desagregação do solo, especialmente sob arroz em cultivo com uso de enxada rotativa, em comparação a um Gleissolo sob vegetação nativa.

2. A análise micromorfológica evidencia que parte da compactação ocorre em consequência da diminuição do volume de grandes bioporos preenchidos com microagregados granulares.

3. Há forte perda dos teores e estoques de $\mathrm{N}$ e especialmente de COS, em Gleissolos cultivados, em comparação ao Gleissolo sob mata, em razão da decomposição orgânica acelerada pelo cultivo e do menor aporte de resíduos.

\section{Agradecimentos}

À Coordenação de Aperfeiçoamento de Pessoal de Nível Superior (Capes) e ao Conselho de Desenvolvimento Científico e Tecnológico (CNPq), pela concessão de bolsa PEC-PG; ao CNPq, pela concessão de bolsa de produtividade; e à Fundação de Amparo à Pesquisa do Estado de Minas Gerais (Fapemig, Projeto CAG-APQ 00720-12), pelo apoio financeiro.

\section{Referências}

ABREU, E.M.A. de; FERNANDES, A.R.; RUIVO, M. de L.P. Variação temporal e vertical de atributos químicos de um Gleissolo do rio Guamá cultivado com canaranas. Revista Brasileira de Ciência do Solo, v.31, p.277-285, 2007. DOI: 10.1590/ S0100-06832007000200010.

BEUTLER, N.A.; MUNARETO, J.D.; GRECO, A.M.F.; POZZEBON, B.C.; GALON, L.; GUIMARÃES, S.; BURG, G.; SCHMIDT, M.R.; DEAK, E.A.; GIACOMELI, R.; ALVES, G. da S. Manejo do solo, palha residual e produtividade de arroz irrigado por inundação. Semina: Ciências Agrárias, v.35, p.1153-1162, 2014. DOI: 10.5433/1679-0359.2014v35n3p1153.

BURLIGA, A.L.; TORGAN, L.C.; NÓBREGA, E.A. de; BEAUMORD, A.C.; COSTA, C.O. da; YAMAUTI, D.V. Diatomáceas epilíticas do rio Itajaí-Mirim, Santa Catarina, Brasil. Acta Scientiarum. Biological Sciences, v.27, p.415-221, 2005. DOI: $10.4025 /$ actascibiolsci.v27i4.1276. 
BRASIL. Departamento Nacional de Meteorologia. Normais climatológicas (1961-1990). Brasília: Embrapa-SPI, 1992.

CLAESSEN, M.E.C. (Org.). Manual de métodos de análise do solo. 2.ed. rev. e atual. Rio de Janeiro: Embrapa-CNPS, 1997. 212 p. (Embrapa-CNPS. Documentos, 1).

FAGERIA, N.K.; CARVALHO, G.D.; SANTOS,A.B.; FERREIRA, E.P.B.; KNUPP, A.M. Chemistry of lowland rice soils and nutrient availability. Communications in Soil Science and Plant Analysis, v.42, p.1913-1933, 2011. DOI: 10.1080/00103624.2011.591467.

FAJARDO, J.D.V.; SOUZA, L.A.G. de; ALFAIA, S.S. Características químicas de solos de várzeas sob diferentes sistemas de uso da terra, na calha dos rios Baixo Solimões e Médio Amazonas. Acta Amazonica, v.39, p.731-740, 2009. DOI: 10.1590/S0044-59672009000400001.

GUIMARÃES, D.V.; GONZAGA, M.I.S.; SILVA, T.O. da; SILVA, T.L. da; DIAS, N. da S.; MATIAS, M.I.S. Soil organic matter pools and carbon fractions in soil under different land uses. Soil and Tillage Research, v.126, p.177-182, 2013. DOI: 10.1016/j. still.2012.07.010.

KÖGEL-KNABNER, I.; AMELUNG, W.; CAO, Z.; FIEDLER, S.; FRENZEL, P.; JAHN, R.; KALBITZ, K.; KÖLBL, A.; SCHLOTER, M. Biogeochemistry of paddy soils. Geoderma, v.157, p.1-14, 2010. DOI: 10.1016/j.geoderma.2010.03.009.

LOPES, E.L.N.; FERNANDES, A.R.; GRIMALDI, C.; RUIVO, M. de L.P.; RODRIGUES, T.E.; SARRAZIN, M. Características químicas de um Gleissolo sob diferentes sistemas de uso, nas margens do rio Guamá, Belém, Pará. Boletim do Museu Paraense Emílio Goeldi: Ciências Naturais, v.1, p.127-137, 2006.

OLK, D.C.; SAMSON, M.I.; GAPAS, P. Inhibition of nitrogen mineralization in young humic fractions by anaerobic decomposition of rice crop residues. European Journal of Soil Science, v.58, p.270-281, 2007. DOI: 10.1111/j.1365-2389.2006. 00836.x.

MENTGES, M.I.; REICHERT, J.M.; GUBIANI, P.I.; REINERT, D.J.; XAVIER, A. Alterações estruturais e mecânicas de solo de várzea cultivado com arroz irrigado por inundação. Revista Brasileira de Ciência do Solo, v.37, p.221-231, 2013. DOI: 10.1590/S0100-06832013000100023.

NASCIMENTO, P.C. do; BAYER, C.; SILVA NETTO, L. de F. da; VIAN, A.C.; VIEIRO, F.; MACEDO, V.R.M.; MARCOLIN, E. Sistemas de manejo e a matéria orgânica de solo de várzea com cultivo de arroz. Revista Brasileira de Ciência do Solo, v.33, p.1821-1827, 2009. DOI: 10.1590/S0100-06832009000600030.
NIMMO, J.R.; PERKINS, K.S. Aggregate stability and size distribution. In: DANE, J.H.; TOPP, G.C. (Ed.). Methods of soil analysis: part 4: physical methods. Madison: Soil Science Society of America, 2002. p.317-328. DOI: 10.2136/ sssabookser5.4.c14.

PÁDUA, E.J. de; GUERRA, A.R.; ZINN, Y.L. Modelagem da densidade do solo em profundidade sob vegetação nativa em Minas Gerais. Revista Brasileira de Ciência do Solo, v.39, p.725-736, 2015. DOI: $10.1590 / 01000683$ rbcs20140028.

ROSA, C.M. da; CASTILHOS, R.M.V.; PAULETTO, E.A.; PILLON, C.N.; LEAL, O. dos A. Conteúdo de carbono orgânico em Planossolo Háplico sob sistema de manejo do arroz irrigado. Revista Brasileira de Ciência do Solo, v.35, p.1769-1776, 2011. DOI: $10.1590 /$ S0100-06832011000500031.

SOUSA, R.O. de; VAHL, L.C.; OTERO, X.L. Química dos solos alagados. In: MELO, V.F., ALLEONI, L.R.F. (Ed.). Química e mineralogia do solo. Viçosa: Sociedade Brasileira de Ciência do Solo, 2009. v.2, p.485-528.

STOOPS, G. Guidelines for analysis and description of soil and regolith thin sections. Madison: Soil Science Society of America, 2003.

THOMAS, M.F. Geomorphology in the Tropics: a study of weathering and denudation in low latitudes. Chichester: J. Wiley and Sons, 1994. 460p.

TROW, R.A.J. (Coord.) Nota explicativa das folhas Varginha (SF.23-V-D-VI) [e] Itajubá (SF.23-Y-B-III). Brasília: CPRM, 2008.

YAN, Y.; TIAN, J.; FAN, M.; ZHANG, F.; LI, X.; CHRISTIE, P.; CHEN, H.; LEE, J.; KUZYAKOV, Y.; SIX, J. Soil organic carbon and total nitrogen in intensively managed arable soils. Agriculture, Ecosystems and Environment, v.150, p.102-110, 2012. DOI: 10.1016/j.agee.2012.01.024.

YAN, X.; ZHOU, H.; ZHU, Q.H.; WANG, X.F.; ZHANG, Y.Z.; YU, X.C.; PENG, X. Carbon sequestration efficiency in paddy soil and upland soil under long-term fertilization in southern China. Soil and Tillage Research, v.130, p.42-51, 2013. DOI: 10.1016/j. still.2013.01.013.

ZHANG, H.; DING, W.; HE, X.; YU, H.; FAN, J.; LIU, D. Influence of 20-year organic and inorganic fertilization on organic carbon accumulation and microbial community structure of aggregates in an intensively cultivated sandy loam soil. PLoS ONE, v.9, p.e92733, 2014. DOI: 10.1371/journal.pone.0092733.

Recebido em 17 de fevereiro de 2016 e aprovado em 2 de junho de 2016 